\title{
The phase-variable pilus-associated protein PilC is commonly expressed in clinical isolates of Neisseria gonorrhoeae, and shows sequence variability among strains
}

\author{
Marianne Bäckman, † Helena Källström and Ann-Beth Jonsson
}

Microbiology and Tumorbiology Center, Karolinska Institutet, S-171 77 Stockholm, Sweden
Author for correspondence: Ann-Beth Jonsson. Tel: +468728 71 74. Fax: +468342651. e-mail: Ann-Beth.Jonsson@mtc.ki.se

\begin{abstract}
PilC is a phase-variable protein associated with pilus-mediated adherence of pathogenic Neisseria to target cells. In this study, 24 strains of Neisseria gonorrhoeae with known epidemiological data were examined for expression of PilC. All strains produced PilC independently of serovar and site of isolation. To investigate whether the PilC protein is conserved or variable among gonococcal strains, the complete nucleotide sequence of pilC in four strains, isolated from either rectum, throat or blood, was determined. The deduced amino acid sequence in these strains differed from each other and from the two PilC proteins of $\boldsymbol{N}$. gonorrhoeae MS11. These data demonstrate that PilC is commonly expressed, but the PilC sequence may vary among gonococcal strains.
\end{abstract}

Keywords: Neisseria gonorrhoeae, PilC, pili, adherence

\section{INTRODUCTION}

Surface-exposed antigens of Neisseria gonorrboeae can have highly variable structural expression, including differences in their pili, opacity proteins and lipooligosaccharides (Lambden et al., 1981; Hagblom et al., 1985; Diaz \& Heckels, 1982; Barritt et al., 1987; Mandrell et al., 1986). Pili of N. gonorrboeae are a major virulence factor and promote attachment of the bacteria to eukaryotic cells (Swanson, 1973; Buchanan $\&$ Pearce, 1976). Adherence of piliated $\left(\mathrm{P}^{+}\right)$bacteria can be modulated by sequence changes in the major pilus subunit protein, PilE (Virji \& Everson, 1981;Virji et al., 1982, 1992, 1993; Nassif et al., 1993; Rudel et al., 1992; Jonsson et al., 1994).

PilC is a $110 \mathrm{kDa}$ pilus-associated minor outer-membrane protein involved in pilus biogenesis and pilusmediated attachment (Jonsson et al., 1991, 1992; Rudel et al., 1992, 1995a, b). N. gonorrhoeae strain MS11 contains two pilC genes, pilC1 and pilC2, which are highly homologous but not identical (Jonsson et al.,

† Present address: Swedish Institute of Infectious Disease Control, S-105 21 Stockholm, Sweden.

Abbreviation: TEM, transmission electron microscopy.

The EMBL accession numbers for the sequences reported in this paper are Y13022, AJ001120 and AJ001121.
1991; Rudel et al., 1995a). The expression of PilC is frequently turned on and off by frameshift mutations in a poly $(\mathrm{G})$ tract located within the signal peptide coding region. PilC is involved in pilus biogenesis since pilC double knock-out mutants are non-piliated (Jonsson $e t$ al., 1991; Nassif et al., 1994; Rudel et al., 1995a). Mutants of $N$. gonorrboeae MS11 expressing either PilC1 or PilC2 can both mediate attachment to target cells at equal levels (Jonsson et al., 1994; Rudel et al., 1995a), whereas in Neisseria meningitidis 8013, PilC1, but not PilC2, expression is correlated with adherence to Hec-I-B and HUVEC cell lines (Nassif et al., 1994; Rahman et al., 1997). High PilC expression in the meningococcal strain MC58 is correlated with hyperadherence and superior anchorage of the bacteria to the host cells (Virji et al., 1995). Recently, PilC was suggested to act as an adhesin at the tip of the pilus fibre (Rudel et al., 1995b). The PilC protein is also associated with the bacterial cell surface (Rahman et al., 1997).

In this study, we examined 24 clinical isolates with known serovar and epidemiological data for production of the PilC protein. We also determined the complete pilC nucleotide sequence of four gonococcal strains, isolated from the blood, throat or rectum. Comparison of these sequences with known gonococcal pilC sequences of strain MS11 and the pilC gene of strain FA1090 suggest that there are sequence variations among PilC in gonococcal strains of different origin. 


\section{METHODS}

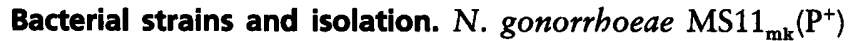
and ${\mathrm{MS} 11_{\mathrm{mk}}}_{\mathrm{s}}\left(\mathrm{P}^{-} \mathrm{n}\right)$ (Swanson et al., 1986) were obtained from
Dr M. Koomey (University of Michigan, Ann Arbor, USA). The specific MS11 ${ }_{m k}$ used in our studies is designated

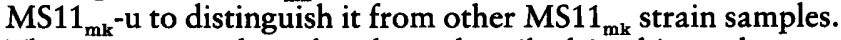
The remaining clinical isolates described in this study were

Table 1. Characteristics of $\boldsymbol{N}$. gonorrhoeae strains

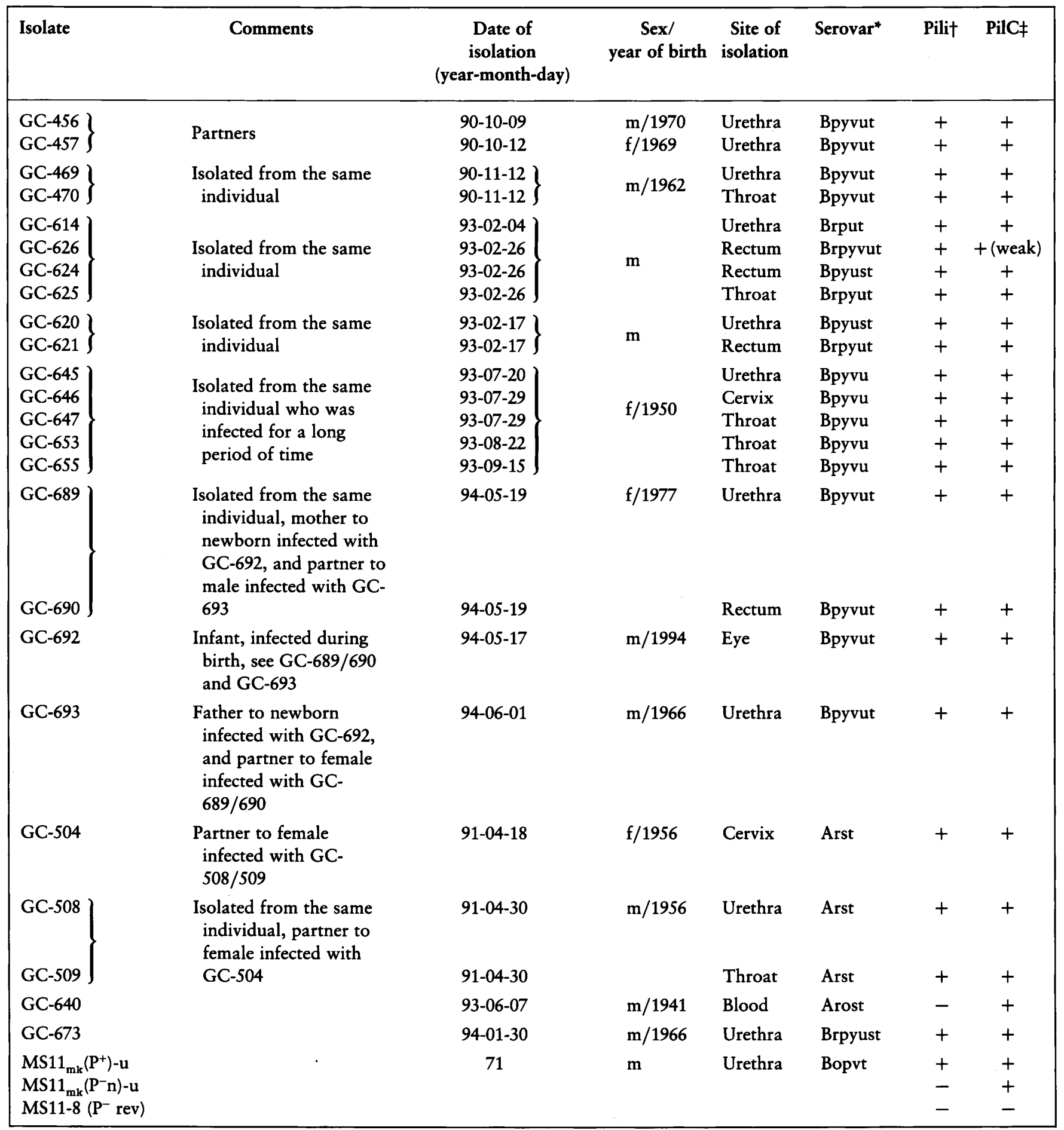

* The strains were classified into serovars with mAbs directed to PI (Ph-panel, Boule Diagnostics) (Knapp et al., 1984; Sandström et al., 1985).

† Determined by TEM.

$\ddagger$ Determined by immunoblotting. 
Table 2. Primers used in this study

\begin{tabular}{|c|c|c|}
\hline Primer & DNA sequence & $\begin{array}{l}\text { Position in } \\
\text { GC-640 pilC }\end{array}$ \\
\hline C103 & $5^{\prime}$ TCATTCGACAATACCGAT $3^{\prime}$ & $264-281$ \\
\hline C105 & $5^{\prime}$ CAGGCTACTCCTACACCG 3' & $430-447$ \\
\hline C106 & $5^{\prime}$ GCAGATCATCCAACAAAT $3^{\prime}$ & $658-675$ \\
\hline C107 & $5^{\prime}$ TCGTCCTGTCGTCTCGAC 3' & $896-879$ \\
\hline C108 & $5^{\prime}$ AATATATCGTCATTACCG $3^{\prime}$ & $1457-1474$ \\
\hline C104 & $5^{\prime}$ TTGACGATGTCGCCCAAA $3^{\prime}$ & $1597-1580$ \\
\hline C208 & $5^{\prime}$ TTCCTCGCCTCCGGTTAT 3' & $2100-2117$ \\
\hline C112 & $5^{\prime}$ TGGCAGACAAACGCGTCG $3^{\prime}$ & 2413-2430 \\
\hline $\mathrm{C} 800$ & $5^{\prime}$ CGGATACGGACAAATGTG $3^{\prime}$ & 2734-2751 \\
\hline C206 & $5^{\prime}$ GTTTACGACAAGCCGGTT $3^{\prime}$ & 2943-2960 \\
\hline C1 & $5^{\prime}$ CCGCGAAGGCAAACTTAAGGAAT 3' & $-21^{*}-2$ \\
\hline C14 & $5^{\prime}$ ATTCTGCTTTACCTCGGGCTGGTT 3' & $164-141$ \\
\hline C30 & $5^{\prime}$ CAAACCCATCAATACGCT $3^{\prime}$ & $105-122$ \\
\hline C100 & $5^{\prime}$ GTCGCCCACATAGCCTTT 3' & 1811-1794 \\
\hline C31 & $5^{\prime}$ GGGTATTTGGCAACCGCCG $3^{\prime}$ & $1620-1638$ \\
\hline $\mathrm{C} 4$ & $5^{\prime}$ TTGCCGCCCCCCTCCCGAAAAAGC 3' & $3259-3236^{*}$ \\
\hline
\end{tabular}

* Approximate location and size. The primers designed from the MS11 pilC1 sequence are located outside the obtained GC-640 pilC sequence.

isolated from patient samples at the Department of Microbiology Stockholm Söder Hospital, Stockholm, Sweden, with the exception of GC-692 obtained from Dr S. Ringertz, Karolinska Hospital, Stockholm, Sweden. The strains were verified as previously described (Bäckman et al., 1995). The strains were classified into serovars with mAbs directed against PI (Ph-panel, Boule Diagnostics) (Knapp et al., 1984; Sandström et al., 1985) and the antigens were prepared as previously described (Bäckman et al., 1985). The strains were passaged two to four times on haematin agar plates [36 g GCII agar base (BBL), $83 \mathrm{ml}$ horse blood (National Veterinary Institute), 2 ampoules yeast autolysate (Oxoid product no. SR105B) per litre] before being stored at $-70^{\circ} \mathrm{C}$. The characteristics of the strains are shown in Table 1 . The control strain $\mathrm{MS} 11_{\mathrm{mk}}\left(\mathrm{P}^{+}\right)$-u produces pili and $\mathrm{PilC}\left(\mathrm{P}^{+}, \mathrm{PilC}^{+}\right)$, the MS11 ${ }_{m k}\left(\mathrm{P}^{+}\right)$-u variant $8\left(\mathrm{P}^{-}, \mathrm{PilC}^{-}\right)$is a spontaneous revertible derivative of $\mathrm{MS}_{11}{ }_{\mathrm{mk}}\left(\mathrm{P}^{+}\right)-\mathrm{u}$ (Jonsson et al., 1992). These strains are referred to as MS11 and MS11-8 in the text. The strains were grown on GC agar [GC medium base with Kellogg's supplement (Jonsson et al., 1991)].

Immunoblotting. Gonococcal cells from a GC agar plate were harvested in PBS $(0.145 \mathrm{M}$ sodium chloride, $0.15 \mathrm{M}$ sodium phosphate) and the concentration was adjusted to $\mathrm{OD}_{600} 5 \cdot 0$. Ten microlitres whole cell lysates of each strain were electrophoresed on SDS-PAGE gels (Laemmli, 1970). The proteins were transferred onto a nitrocellulose filter and tested for reaction with polyclonal anti-PilC serum (Towbin et al., 1979). The polyclonal anti-PilC serum was directed against PilC2 of MS11 and was prepared as previously described (Jonsson et al., 1991).

Transmission electron microscopy (TEM). For TEM, strains of gonococci were grown overnight on GC agar plates, suspended in $10 \mathrm{mM}$ Tris/ $\mathrm{HCl}$ ( $\mathrm{pH} 7.5$ ), $10 \mathrm{mM} \mathrm{MgCl}$ buffer and overlaid on 200-mesh carbon-coated copper grids for $10 \mathrm{~min}$. The grids were washed with water, negatively stained with $1 \%$ sodium silicotungstate and examined in a Philips $100 \times x$ microscope.
Assays for adherence to cultured ME180 cells. ME180 (ATCC HTB33), an epithelial-like cell line derived from a human cervical carcinoma was grown in McCoy's 5A medium supplemented with $10 \%$ foetal calf serum and $1 \%$ L-glutamine at $37^{\circ} \mathrm{C}$ in $5 \% \mathrm{CO}_{2}$. For adherence assays, the cells were seeded in four-well tissue-culture chamber slides (Nunc) and incubated at $37^{\circ} \mathrm{C}$ for $2 \mathrm{~d}$. The bacterial isolates were taken from the $-70^{\circ} \mathrm{C}$ storage supply, and several colonies of each strain were streaked on a GC agar plate for use in the binding assay. Non-confluent layers of ME180 cells were infected with $10^{7}$ bacteria $\mathrm{ml}^{-1}$ for $1 \mathrm{~h}$ at $37^{\circ} \mathrm{C}$ in $5 \% \mathrm{CO}_{2}$. The cells were washed four times with minimal essential medium (MEM) and fixed with $0.3 \%$ glutaraldehyde. After blocking with $2 \%$ BSA for $1 \mathrm{~h}$, attached bacteria were detected with gonococcal antiserum (diluted $1: 200$ in $0.2 \% \mathrm{BSA}$ in $\mathrm{PBS}, \mathrm{pH} 7.4$ ) for $30 \mathrm{~min}$, washed three times in PBS, incubated with FITCconjugated anti-rabbit IgG (Sigma) diluted 1:1000 in PBS for $60 \mathrm{~min}$ and finally washed three times in PBS. The mean number of attached bacteria per cell was determined by counting the bacteria on 100 randomly chosen cells. The binding assay was performed on three independent occasions, with bacteria taken from the $-70^{\circ} \mathrm{C}$ storage vial each time.

PCR amplification. Genomic DNA was prepared as previously described (Jonsson et al., 1991). The PCR reactions were carried out according to the protocol of Perkin Elmer Cetus. Chromosomal DNA from GC-640 was used as the template and the primers used were synthesized according to the DNA sequence of MS11 pilC1 (Jonsson et al., 1995) by Pharmacia Biotech. DNA polymerase from Dynazyme was used in the PCR assay. The samples were subjected to 30 cycles of $1 \mathrm{~min}$ at $94^{\circ} \mathrm{C}, 1 \mathrm{~min}$ at $44^{\circ} \mathrm{C}$ and $3 \mathrm{~min}$ at $72^{\circ} \mathrm{C}$. The samples were separated by agarose gel electrophoresis and the sizes of the fragments obtained were calculated by comparing with DNA molecular mass markers (Boehringer Mannheim). DNA fragments of the expected size were cut out, electroeluted and purified by Elutip-d (Schleicher \& Schuell). 
DNA sequencing. The pilC gene of GC-640 was PCRamplified in three overlapping fragments. Fragment 1 (185 bp) and fragment $2(1707 \mathrm{bp})$ were PCR-amplified using the primer pairs $\mathrm{C} 1, \mathrm{C} 14$ and $\mathrm{C} 30, \mathrm{C} 100$, respectively. These two fragments were ligated into M13mp18 and M13mp19 vectors and transformed into Escherichia coli XL1-Blue supercompetent cells (Epicurian Coli, Stratagene) according to the manufacturer's instructions. Fragment 3 (1571 bp), containing the 3 ' end of pilC, was amplified using the primers C31 and $\mathrm{C} 4$, and sequenced directly. Sequencing was performed using the T7 Sequencing kit (Pharmacia) for manual sequencing, or the Taq DyeDeoxy Terminator Cycle Sequencing kit (Applied Biosystems) for automated sequencing. The fragments were sequenced by primer walking using oligonucleotides synthesized according to the MS11 pilC1 sequence or oligonucleotides synthesized according to the sequence of GC-640 obtained in the previous step (Table 2). More than one M13 clone was sequenced, and no sequence differences between clones were found. The pilC gene of GC-647, GC-653 and GC626 was PCR-amplified using primers $\mathrm{C} 1$ and C4 (Table 2), and then gel-purified. Automated sequencing of the PCR products was performed using internal pilC primers (Table 2) and the Taq DyeDeoxy Terminator Cycle Sequencing kit (Applied Biosystems). The sequences obtained were analysed with the help of the Wisconsin Sequence Analysis package, version 8.0 (CGC 8) (Genetics Computer Group, Madison, WI, USA).

The pilE gene was PCR-amplified and sequenced directly as previously described (Jonsson et al., 1994).

\section{RESULTS}

\section{Expression of PilC in clinical isolates of N. gonorrhoeae}

We examined 24 strains of $N$. gonorrhoeae (Table 1 ) for the production of PilC. Whole bacterial cell lysates were examined by immunoblotting using a PilC-specific antiserum, and all isolates demonstrated a $105-110 \mathrm{kDa}$ band, indicating that PilC was expressed. The negative control used was MS11-8, which is a spontaneous nonpiliated, PilC variant of $\mathrm{MS}^{-} 1_{\mathrm{mk}}\left(\mathrm{P}^{+}\right)$-u. This variant reverts to $\mathrm{P}^{+}, \mathrm{PilC}^{+}$at a frequency of $10^{-3}-10^{-4}$ per cell per generation, so it presumably had a minor population of PilC-expressing bacteria. However, this was not detected by immunoblotting. We thus concluded that the PilC-positive signal of the isolates came from true $\mathrm{PilC}^{+}$bacteria and not from $\mathrm{P}^{-}, \mathrm{PilC}^{-}$clones containing a small population of revertants. Isolate GC-626 displayed a weaker band in immunoblots, indicating that PilC production was down-regulated in this clone or that the PilC sequence of this isolate was very different compared to that of PilC2 of $N$. gonorrhoeae MS11, against which the antiserum was raised.

\section{Variation in adherence to ME180 cells}

Twenty-three of the strains in Table 1 expressed pili as determined by TEM, and one strain, GC-640, isolated from blood was not able to produce pili. One set of related strains, GC-645, GC-646, GC-647, GC-653 and

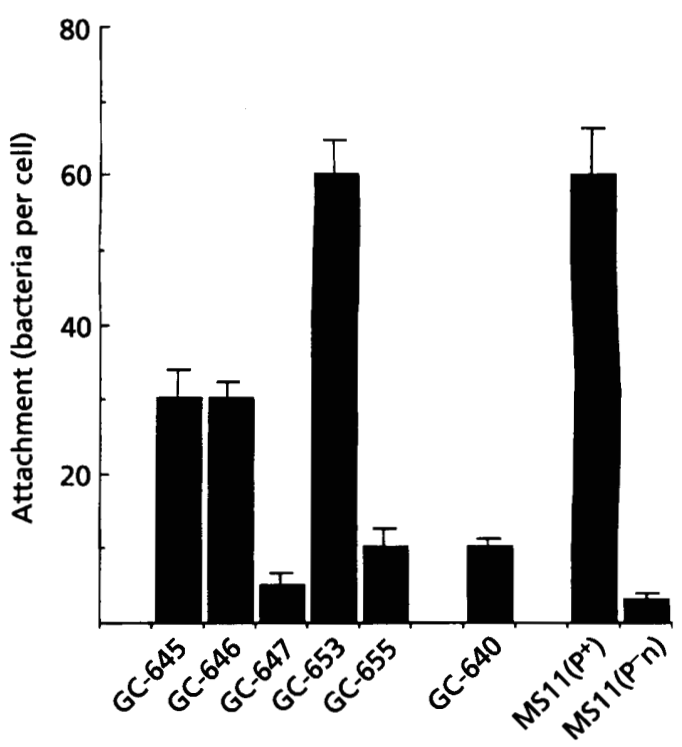

Fig. 1. Attachment of $\boldsymbol{N}$. gonorrhoeae clinical isolates to the epithelial cell line ME180. The bacteria $\left(10^{7}\right.$ per well) were added to a non-confluent layer of ME180 cells and incubated at $37^{\circ} \mathrm{C}$ in $5 \% \mathrm{CO}_{2}$ for $1 \mathrm{~h}$. Mean values and SD of three experiments are shown.

GC-655, was studied for adherence to the epithelial cervical cell line ME180. These strains were isolated from a patient not responding to antibiotic treatment, and differed from other sets of related strains in that they did not produce Opa, as detected by SDS-PAGE and Coomassie-brilliant-blue-staining of outer-membrane preparations. Non-confluent layers of cells were infected with $10^{7}$ bacteria for $1 \mathrm{~h}$ and bound bacteria were detected by immunofluorescence microscopy. All five strains were of identical serovar, but differed in attachment levels from 5 to 60 bacteria per cell (Fig. 1). Southern hybridization and PCR amplification revealed that the strains carried only one copy of pilC (data not shown). According to careful examination by TEM, this set of strains produced equal amounts of pili. However, the strains contained different pilE gene sequences relative to each other (Fig. 2), as determined by direct sequencing of PCR-amplified fragments. Therefore, it is likely that the variation in adherence was due to PilE variation. These data are in agreement with previous studies in vitro, which showed that sequence changes in PilE lead to variation in tropism to target cells (Virji et al., 1993; Rudel et al., 1992; Jonsson et al., 1994; Nassif et al., 1993). The non-piliated DGI (disseminated gonococcal infection) strain GC-640 expressed Opa, and bound to ME180 cells at levels of 10 bacteria per cell, which is higher than the non-piliated MS11 control strain with five bacteria per cell. Opa proteins of $N$. gonorrboeae mediate adherence and invasion into target cells (Virji \& Everson, 1981; Kupsch et al., 1993). It is therefore likely that the increased adherence of GC-640 was due to expression of Opa. 


$\begin{array}{cccccccccc} & 50 & 60 & 70 & 80 & 90 & 100 & 110 & 120 & 130 \\ \text { GC-645 VTEYYLNNGEWPKDNTSAGVASPPSDIKGKYVQSVTVAKGVVTATMNSSNVNKEIKDKKLSLWAKRENGSVKWFCGRPVRANADNDTVTDGNGGKNNAIETKHLPSTCRDKASDAK* }\end{array}$

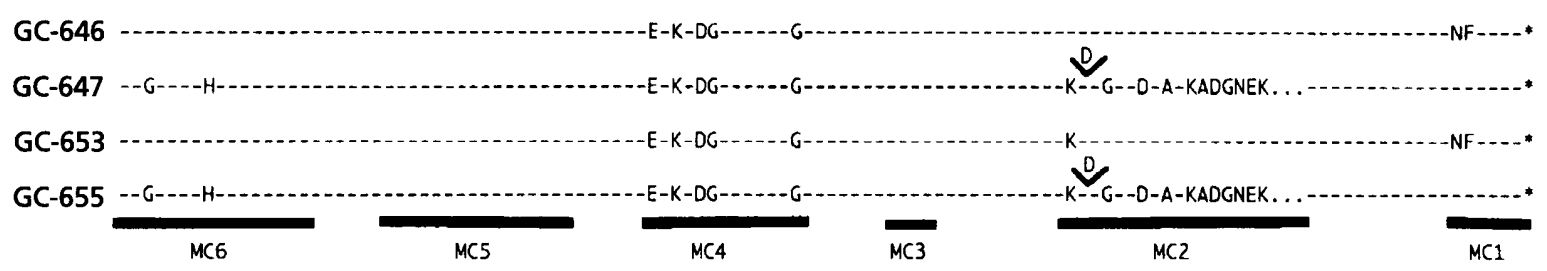

Fig. 2. Deduced amino acid sequence of pilE in a set of related strains. The pilE coding region was PCR-amplified and sequenced directly. The six variable mini-cassettes are marked MC1-MC6. Amino acids that differ from PilE of GC-645 are shown. Identical stretches of amino acids are indicated by dashes. Numbering above the sequences starts at position 1 of the mature PilE protein.

\section{pilC in gonococcal strains differs from pilC in strain MS11}

To determine the variability of pilC among gonococcal strains from different sites of isolation, the entire pilC gene was sequenced in four strains: GC-640, GC-626, GC-647 and GC-653. Strain GC-640 was isolated from blood and carried only one pilC gene, as determined by Southern blotting of ClaI-digested genomic DNA, and by ClaI digestion of PCR-amplified pilC fragments of GC-640 (data not shown). Strain GC-626, isolated from the rectum, expressed low levels of PilC in immunoblots. The two related strains, GC-647 and GC-653, isolated from the throat, bound at low (5 bacteria per cell) or high (60 bacteria per cell) numbers to ME180 cells. For DNA sequencing of GC-640, PCR was used to amplify the gene in three overlapping pieces. Two fragments of $1.7 \mathrm{~kb}$ and $1.5 \mathrm{~kb}$ covered the region encoding the mature protein, and overlapped by $250 \mathrm{bp}$. The third fragment of $185 \mathrm{bp}$ covered the signal peptide coding region. Each fragment was sequenced by primer walking using the oligonucleotides shown in Table 2 . The sequenced pilC gene of GC-640 contained $12 \mathrm{G}$ residues within the poly $(G)$ tract in the signal peptide coding region (EMBL accession number Y13022). The gene showed $84 \%$ homology with pilC1 of MS11 (Jonsson et al., 1995) and $88 \%$ homology with pilC2 (Rudel et al., 1995a) of MS11, according to analysis with the GCG 8 software. In the case of GC-626, GC-647 and GC-653, the complete pilC gene was PCR-amplified and sequenced directly by using internal primers. The pilC gene of GC-647 was identical to pilC of GC-653 (EMBL accession number Y13021), which proved that pilC sequence variation did not mediate the different levels of adhesion seen. pilC of GC-647/653 is $86 \%$ homologous to MS11 pilC1, and $84 \%$ homologous to MS11 pilC2. This pilC gene sequence carries $10 \mathrm{G}$ residues within the poly $(\mathrm{G})$ tract. GC-626 pilC (EMBL accession number $\mathrm{Y} 13020)$ contains $13 \mathrm{G}$ residues in the poly $(\mathrm{G})$ tract, and showed $89 \%$ homology with pilC1 and $91 \%$ homology with pilC2 of MS11.

\section{The PilC sequence varies among strains}

The deduced amino acid sequences of pilC in GC-640, GC-626 and GC-647/653 are shown in Fig. 3. The mature PilC proteins had a predicted molecular mass of around $110 \mathrm{kDa}$ and an isoelectric point close to 10 . Several variable and conserved regions were identified when comparing the obtained amino acid sequences with MS11 PilC1 and PilC2, and with the preliminary PilC sequence of FA1090 (obtained during the Gonococcal Genome Sequencing project) (B. A. Roe, S. Clifton \& D. W. Dyer, http://dna1.chem.uoknor.edu). The first 50 amino acids and the last 350 amino acids were more conserved than the rest of the protein. PilC of GC-640 was $73 \%$ identical ( $83 \%$ similar) to MS11 PilC1, and $77 \%$ identical ( $84 \%$ similar) to MS11 PilC2. GC-626 PilC was $81 \%$ identical ( $88 \%$ similar) to MS11 PilC1, and $76 \%$ identical ( $84 \%$ similar) to MS11 PilC2. The PilC protein of GC-647/653 was $84 \%$ identical (90\% similar) to MS11 PilC1, and 74\% identical $(83 \%$ similar) to MS11 PilC2. PilC of GC-626 reacted weakly in immunoblots using an antiserum raised against PilC1 of MS11. Since this sequence did not differ more from MS11 PilC1 compared to the other strains, it is likely that the weaker PilC band seen in immunoblots was due to down-regulation in PilC production. Hydrophobic and hydrophilic domains were analysed by the GCG 8 software and showed no apparent variation between the different sequences (data not shown).

\section{DISCUSSION}

The aim of this study was to determine if PilC is expressed in gonococcal strains of different origin, and to determine whether the PilC sequence is conserved or variable. We found that all the 24 clinical isolates expressed PilC, independently of serovar and site of isolation. The DGI strain GC-640 expressed PilC, although pili were not demonstrated by TEM. However, the isolate GC-626 showed a weaker PilC band in immunoblots. Since the pilC sequence of this strain did not show increased variability compared to the other strains examined, it is likely that PilC production may be down-regulated in GC-626. In a previous study of $N$. meningitidis, PilC was detected in $89 \%$ of the mucosal isolates and in $54-60 \%$ of the disseminated isolates studied, as determined by immunoblotting using a PilC antiserum (Virji et al., 1995). It could be that meningococci and gonococci differ in PilC expression. How- 
GC-640 MNKTLKPOVF RHTALYAAIL MFSHTGGGGC AMAQT. . HQY AIVMNERNQP EVKWHGQYQK SQLREKDGER KFTYTNQKTG GTNKNNFISF ONTDTLVSRO

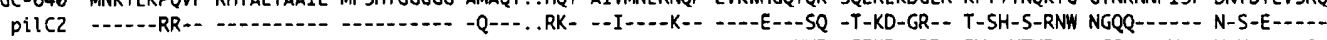

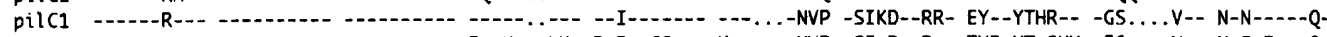
GC-626 -...-R-.. -

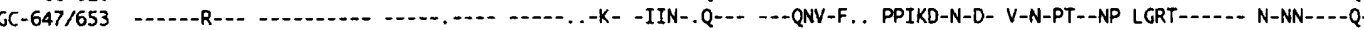

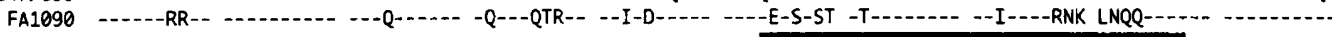

1012150

GC-640 SGTAVFGTAT YLPPYGKVSG FDIAELNKRG NAVNWIHTTR AALSGYSYTG VTCRSGKCRP KLVYKTRFSF DNTGLAKNAG R.LNRHPDPS RENSPIYKLE

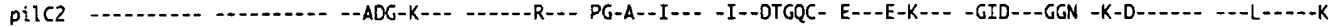

pilC1 -

GC-626 -

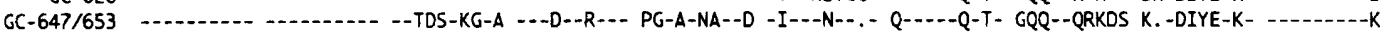

FA1096 -

201

250

300

6C-640 DHPWLGVSFN LGAEGTDKDG RSSNKLVSSF SONNSN..QI IVCTTEGHRI SLGDWQREHT AMAYYLNAKL HLLDKKQIEN IAPGKTVQLG TLRPRVETTG

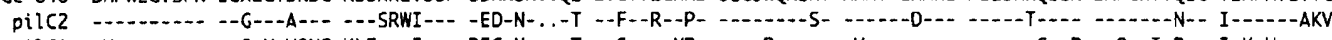

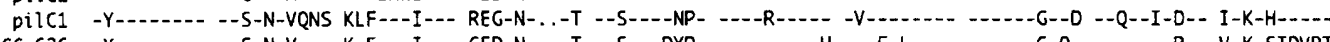

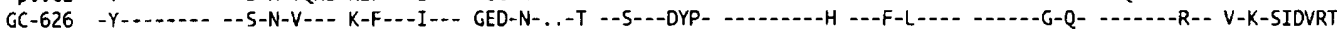

GC-647/653 -Y Y...... -.S

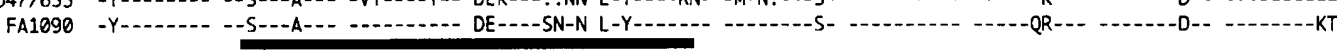

301
GC-640

pilC2 -RKW.DL-N- --K-D-K-T- Q-P-K-G-.. .............PKS. -L. -

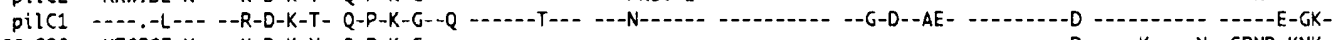

GC-626 -NTGFGF-N- --K-D-K-N- Q-P-K-G-.

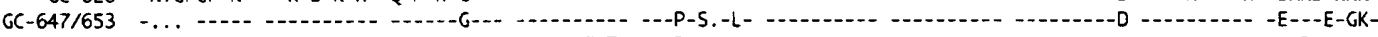

FA1090 NNWGN L-S - .......-..-

$401 \quad 450$

GC-640 GRHSLAALNA QDIKSREPNF NSRQTVIRLP GGVYKISSGK NGGRVAGI.. .. NGNDGKND TFGIYKDKLV TPEADEWSNI LLPWTARYYG NDDIFKTFNQ

pilC2 -

pilC1 --Y--KS--D GE-.--Q-S- -G---I---D D--HL-KLNG SKDE--AFVN LNGN-T---- ----V-EAN- NLD----KKV -.---V-GPD --NK--SI--

GC-626 --Y--OP--E NE----Q--S- TI ---II---D D--HL-RLSR ARDE-IDFVN LNGN-T---- ----V-EAN- NLN----KKV --.--V-GPD --NK--SI-.

GC-647/653 --Y--KP-SE NE--VK--R- -R-------D S--QL-NLNW -NDE-VTF.. . .G--A-N-G ----V-EAD- NL-----KXV -----V-AP- --NK--SI-R

FA1090

(1)

501

550

600

GC-640 PNNKKQSDKK QYSQKYRIRT KEDDNDN.RD LGOIVNSPIT AVGGYLATSA NDGMVHIFKK NGT.DQRGYE LKLSYIPGTM PRKDIESN. . ... DSTLAKE

pilC2 --S-T-NG--

pilC1 KPE-...... .--R--.. . . . --NGN-- -

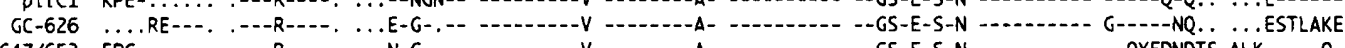

GC-647/653 EPG-...... .--R----. . -N-G-.-- -

FA1090 --S-T-NG-$601 \quad 650 \quad 700$

GC-640 LRAFAEKGYV GDRYGVGGF VLCPL. QMTS QAEHFFMCGA MALGGRGVYA LDSRKINDFF FPVGRPLFGV KDGDNNGKNR ...VKVDLGY TRRTRNFGTP

pilC2 - - T -....-- - - - RRITDDQD KQK-..--F-- -G--.--A-- --LS--DSSN LT. -VSM-D- QNDK--NN-K NDNNR-K--- -VG-PQI-KT

pilC1 …..... - -

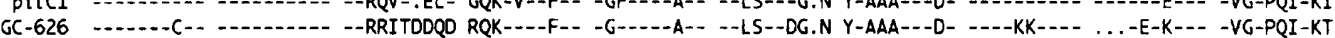

GC-647/653 --T-1-

FA1090

701

750

800

GC-640 PKRGKYSVSL GSGYWGKNIG SGDNKTALYY YDLGNTLGTP IAKIDVKDGK GGLSSPTLVD KDLDGTADIA YAGDRGGYMY RLDLSNSDPS KCSVSTIFEA

pilC2 QN. - - AAF- A--AA--- - -

pilC1 RN. - - AAF- A---AA-K-D DST -

GC-626 QN. - - AF- A--AA-H-A -PT-.....

GC-647/653 QN. -- AF- A---AA-D-D DPT-

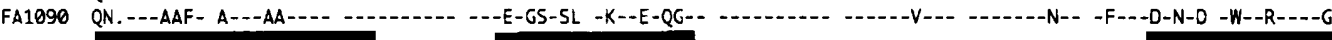

$8010950 \quad 900$

GC-640 AKPITSVAAV SRLADKRVAI FGTARYLTEE DVLDRKEQYI YGIFDODKGT ..VKVTVQNG TAGGLLEQVL KEENKTLFL. .NKGSVGSQS KGWIVKLKEC

pilCZ D-.--AP-- -.-.-.--V - -.-GSD-S-Q - ---TDK--- - -

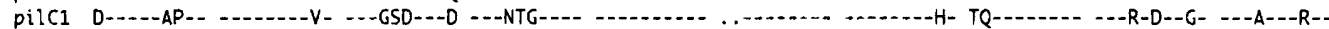

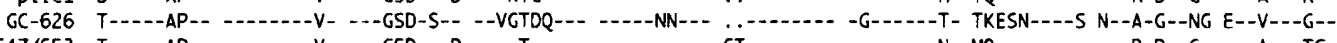

GC-647/653 T-

FA1090 D---AP-D -

901

GC-640 901 QRLTDKPTVV LRTALVTIRS YTGADNCGAQ PAIVVINTAD GGALTPRSAR PIVPOHNS.V AQYSGHKKTA EGKSPPIGCM NKCGKTVCPN GYVDDKADIV

pilC2 E-V-V...... - -

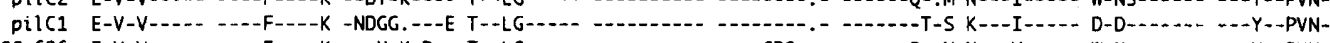

GC-626 E-V-V-.... -.--F----K ---N-K-D-- T--LG-... -

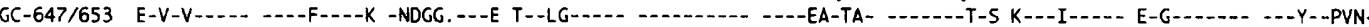

FA1090 --V-V-..-

1001

1050

GC-640 RYLEKRKTDD FPVTADGDAG GSGTFKEGKK PARNNRCFSG KGVRTLLMND LDSLDITGPM CGIKRLSWREVFF*

pilC2 $\rightarrow$ DEK-

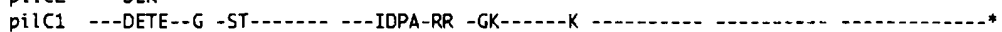

GC-626 --DEK-

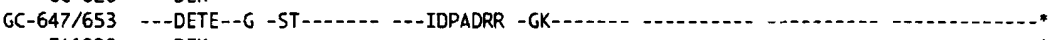

FA1090 --DEK-...

Fig. 3. For legend see facing page. 
ever, a different PilC antiserum was used in the meningococcal study.

The strains demonstrated variation in attachment to ME180 cells. GC-647 and GC-655 adhered very poorly although they were piliated and $\mathrm{PilC}^{+}$. Thus, adherence to ME180 varied even when the amount of PilC detected by immunoblotting was equal. GC-647 (binds poorly to ME180), and GC-653 (binds well to ME180) carry an identical pilC gene, but differ in pilE gene sequence. Therefore, the variation in adherence is most likely due to PilE sequence variation. Sequence variation in the major pilus subunit, PilE, has previously been shown to modulate adherence of both $N$. gonorrhoeae and $N$. meningitidis to target cell lines and tissues (Virji et al., 1992, 1993; Jonsson et al., 1994; Rudel et al., 1992; Nassif et al., 1993).

Some of the strains used in this study were passaged one or two times before being frozen. Therefore, we can not exclude the possibility that the phenotypes expressed by these isolates differed from the in vivo situation. The number of G residues found indicates that GC-640 pilC was out-of-frame. However, expression of PilC in GC640 was demonstrated by immunoblotting. It may be that the pilC gene was in-frame in a subclone of the isolate. It is also possible that during PCR, a frameshift, with loss of a $G$ residue or addition of two $G$ residues, could occur because of the limited proof-reading of the DNA polymerase. Different proportions of in- and outof-frame copies were found in an earlier study (Jonsson et al., 1991) involving strain MS11, which was found to express PilC. Among the strains studied, we found that only GC-640 and the set of five related strains, i.e. GC645, GC-646, GC-647, GC-653 and GC-655, carry one pilC locus. The remaining isolates contained two pilC alleles, according to PCR-amplification with pilC1- and pilC2-specific primers.

The conserved and variable domains in PilC could represent antigenic variation of the PilC protein. PilC has been suggested as a vaccine candidate, but the antigenicity of the stable domains has to be investigated to determine whether the conserved domains are exposed to the human immune system. If PilC is an important adhesin which interacts with a specific receptor on eukaryotic cells, the receptor-binding domain of the PilC protein should be conserved and be a potential target for development of a vaccine. Further studies are required to determine if the variable and conserved regions of PilC are surface-exposed and to determine the possible clinical importance of the demonstrated variation.

\section{ACKNOWLEDGEMENTS}

Lenore Johansson is acknowledged for excellent technical assistance with the electron microscopy work. The Gonococcal Genome Sequencing project, and B. A. Roe, S. Clifton and D. W. Dyer are gratefully acknowledged for making the preliminary FA1090 pilC sequence available. This work was supported by grants from the Swedish Medical Research Council (Dnr 10846), Swedish Society of Medicine, Magnus Bergvalls Stiftelse, Ảke Wibergs Stiftelse, Anders Otto Svärds Stiftelse and Sven och Dagmar Salens Stiftelse. M.B. was supported by a personal grant from the Karolinska Institute.

\section{REFERENCES}

Bäckman, M., Rudén, A.-K. M., Bygdeman, S. M., Jonsson, A., Ringertz, O. \& Sandström, E. G. (1985). Gonococcal serovar distribution in Stockholm, with special reference to multiple infections and infected partners. Acta Pathol Microbiol Immunol Scand Sect B Microbiol 93, 225-232.

Băckman, M., Jacobson, K. \& Ringertz, S. (1995). The virgin population of Neisseria gonorrhoeae in Stockholm has decreased and antimicrobal resistance is increasing. Genitourin Med 71, 234-238.

Barritt, D. S., Schwalbe, R. S., Klapper, D. G. \& Cannon, J. G. (1987). Antigenic and structural differences among six proteins II expressed by a single strain of Neisseria gonorrboeae. Infect Immun 55, 2026-2031.

Buchanan, T. M. \& Pearce, W. A. (1976). Pili as mediators of the attachment of gonococci to human erythrocytes. Infect Immun $13,1483-1489$.

Diaz, J.-L. \& Heckels, J. E. (1982). Antigenic variation of outer membrane protein II in colonial variants of Neisseria gonorrhoeae P9. J Gen Microbiol 128, 585-591.

Hagblom, P., Segal, E., Billyard, E. \& So, M. (1985). Intragenic recombination leads to pilus antigenic variation in Neisseria gonorrboeae. Nature 315, 156-158.

Jonsson, A.-B., Nyberg, G. \& Normark, S. (1991). Phase variation of gonococcal pili by frameshift mutation in pilC, a novel gene for pilus assembly. $E M B O J 10,477-488$.

Jonsson, A.-B., Pfeifer, J. \& Normark, S. (1992). Neisseria gonorrhoeae PilC expression provides a selective mechanism for structural diversity of pili. Proc Natl Acad Sci USA 89, 3204-3208.

Jonsson, A.-B., Ilver, D., Falk, P., Pepose, J. \& Normark, S. (1994). Sequence changes in the pilus subunit lead to tropism variation of Neisseria gonorrboeae to human tissue. Mol Microbiol 13, 403-416.

Jonsson, A.-B., Rahman, M. \& Normark, S. (1995). Pilus biogenesis gene, pilC, of Neisseria gonorrhoeae: pilC1 and pilC2 are each part of a larger duplication of the gonococcal genome and share upstream and downstream homologous sequences with opa and pil loci. Microbiology 141, 2367-2377.

Knapp, J. S., Tam, M. R., Nowinsky, R. C., Holmes, K. K. \& Sandström, E. G. (1984). Serological classification of Neisseria

Fig. 3. Comparison of gonococcal PilC sequences. Shown are the PilC sequence of $N$. gonorrhoeae strain GC-640 (EMBL accession number Y13022), the PilC2 (Rudel et al., 1995a) and PilC1 (Jonsson et al., 1995) sequences of N. gonorrhoeae strain MS11, the PilC sequence of GC-626 (EMBL accession number Y13020), and the identical PilC sequences of GC-647 and GC-653 (EMBL accession number Y13021). The PilC sequence of $N$. gonorrhoeae FA1090 is preliminary and originates from the Gonococcal Genome Sequencing project (B. A. Roe, S. Clifton \& D. W. Dyer, http://dna1.chem.uoknor.edu). The in-frame versions of the proteins are presented. Thick black lines under the sequences represent variable regions of PilC. Dashes represent amino acids identical to those in the GC-640 sequence and dots represent amino acid gaps. Asterisks mark the ends of the proteins. 
gonorrhoeae with use of monoclonal antibodies to gonococcal outer membrane protein I. J Infect Dis 150, 44-48.

Kupsch, E. M., Knepper, B., Kuroki, T., Heuer, I. \& Meyer, T. F. (1993). Variable opacity (Opa) outer membrane proteins account for the cell tropisms displayed by Neisseria gonorrhoeae for human leukocytes and epithelial cells. EMBO J 12, 641-650.

Laemmli, U. K. (1970). Cleavage of structural proteins during the assembly of the head of bacteriophage T4. Nature 227, 680-685.

Lambden, P. R., Heckels, J. E., McBride, H. \& Watt, P. J. (1981). The identification and isolation of novel pilus types produced by variants of $N$. gonorrboeae $\mathrm{P9}$ following selection in vivo. FEMS Microbiol Lett 10, 339-341.

Mandrell, R. E., Schneider, H., Apicella, M., Zollinger, W., Rice, P. A. \& Griffiss, J. M. (1986). Antigenic and physical diversity of Neisseria gonorrhoeae lipooligosaccharides. Infect Immun 54, 63-69.

Nassif, X., Lowy, J., Stenberg, P., O'Gaora, P., Ganji, A. \& So, M. (1993). Antigenic variation of pilin regulates adhesion of Neisseria meningitidis to human epithelial cells. Mol Microbiol 8, 719-725.

Nassif, X., Beretti, J.-L., Lowy, J., Stenberg, P., O'Gaora, P., Pfeifer, J., Normark, S. \& So, M. (1994). Roles of pilin and PilC in adhesion of Neisseria meningitidis to human epithelial and endothelial cells. Proc Natl Acad Sci USA 91, 3769-3773.

Rahman, M., Källström, H., Normark, S. \& Jonsson, A.-B. (1997). PilC of pathogenic Neisseria is associated with the bacterial cell surface. Mol Microbiol 25, 11-25.

Rudel, T., van Putten, J. P. M., Gibbs, C. P., Haas, R. \& Meyer, T. F. (1992). Interaction of two variable proteins (PilE and PilC) required for pilus-mediated adherence of Neisseria gonorrhoeae to human epithelial cells. Mol Microbiol 6, 3439-3450.

Rudel, T., Boxberger, H.-J. \& Meyer, T. F. (1995a). Pilus biogenesis and epithelial cell adherence of Neisseria gonorrhoeae pilC double knock-out mutants. Mol Microbiol 17, 1057-1071.

Rudel, T., Scheuerpflug, I. \& Meyer, T. F. (1995b). Neisseria PilC protein identified as type- 4 pilus tip-located adhesin. Nature 373, $357-359$.

Sandström, E., Lindell, P., Hărfast, B., Blomberg, F., Ryden, A.-C. \& Bygdeman, S. (1985). Evaluation of a new set of Neisseria gonorrboeae serogroup W-specific monoclonal antibodies for serovar determination. In The Pathogenic Neisseriae, pp. 26-30. Edited by G. K. Schoolnik. Washington, DC: American Society for Microbiology.

Swanson, J. (1973). Studies on gonococcus infection. IV. Pili: their role in attachment of gonococci to tissue culture cells. $J$ Exp Med 137, 571-589.

Swanson, J., Bergström, S., Robbins, K., Barrera, O., Corwin, D. \& Koomey, J. M. (1986). Gene conversing involving the pilin structural genes correlates with pilus + to pilus - changes in Neisseria gonorrboeae. Cell 47, 267-276.

Towbin, H., Staehelin, T. \& Gordon, J. (1979). Electrophoretic transfer of proteins from polyacrylamide gels to nitrocellulose sheets: procedure and some applications. Proc Natl Acad Sci USA 76, 4350-4354.

Virji, M. \& Everson, J. S. (1981). Comparative virulence of opacity variants of Neisseria gonorrboeae. Infect Immun 31, 965-970.

Virji, M., Everson, J. S. \& Lambden, P. R. (1982). Effect of antipilus antisera on virulence of variants of Neisseria gonorrhoeae for cultured epithelial cells. J Gen Microbiol 128, 1095-1100.

Virji, M., Alexandrescu, C., Fergusson, D. J. P., Saunders, J. P. \& Moxon, E. R. (1992). Variations in the expression of pili : the effect on adherence of Neisseria meningitidis to human epithelial and endothelial cells. Mol Microbiol 6, 1271-1279.

Viril, M., Saunders, J. P., Simms, G., Makepeace, K., Maskell, D. \& Fergusson, D. J. (1993). Pilus-facilitated adherence of Neisseria meningitidis to human epithelial and endothelial cells: modulation of adherence phenotype occurs concurrently with changes in primary amino acid sequence and the glycosylation status of pilin. Mol Microbiol 10, 1013-1028.

Virji, M., Makepeace, K., Peak, I., Payne, G., Saunders, J. P., Ferguson, D. J. P. \& Moxon, E. R. (1995). Functional implications of PilC expression in meningococci. Mol Microbiol 16, 10871097.

Received 20 May 1997; revised 20 August 1997; accepted 25 September 1997. 